\title{
Fragmented Practice: Creating and Maintaining Information-Rich Websites in SMEs
}

\author{
Sally Burford \\ News and Media Research Centre, \\ University of Canberra, Australia \\ sally.burford@canberra.edu.au \\ Lisa M. Given \\ School of Information Studies, \\ Research Institute for Professional Practice, Learning and Education, \\ Charles Sturt University, Australia \\ lgiven@csu.edu.au \\ Philip Hider \\ School of Information Studies, \\ Charles Sturt University, Australia \\ phider@csu.edu.au
}

\begin{abstract}
Background. Whilst designing and implementing optimal Web information structures contributes to organisational goals and success, the size and structure of small and medium enterprises (SMEs) make Web information architecture (IA) a challenging task. At the same time, the attitudes and the capabilities of SMEs for online participation are crucial to a robust economy in nations across the world.

Objectives. This research aimed to better understand the context and activity in the development of an information-rich website in SMEs in Australia. The particular issues, obstacles and successes in the practice of IA in SMEs are explored.

Methods. Framed by a multi-case study methodology, this research used SMEs as units of analysis. In an inductive approach to analysis, the data were coded using NVivo software to reveal patterns and themes common across the studied SMEs. Results. The context for the development of online information structures is a fragmented Web development process. Web information structures are not always effective and SMEs are challenged to maintain an IA once a new website is launched.

Contributions. This study suggests that Web IA and its allied practices are severely under-researched and under-theorised in SMEs. Whilst SMEs exert significant effort in the development of an information-rich website, they are poorly informed or influenced by expertise and theory. Staff with the knowledge and attitude needed to embed effective IA in the development and maintenance of the enterprise website are crucial in ensuring that the organisation's online strategy is achieved.
\end{abstract}




\section{INTRODUCTION}

In enterprises of all sizes, the organisation of online information and other aspects of website design are critical activities in creating an effective website. Designing and implementing optimal Web information structures support various enterprise goals and contribute to organisational success. Scholars such as Carree, van Stel, Thurik and Wennekers (2002) and Howcroft (2001) suggest that the development of the Internet and its pervasiveness in society provides an opportunity for small and medium-sized enterprises (SMEs) to flourish and to overcome, to some extent, the economies of scale that favour the larger enterprise. SMEs accommodate $69 \%$ of the Australian workforce and are situated in an ever-expanding digital economy (Australian Communications and Media Authority, 2014). The attitudes and the capabilities of SMEs for online participation are crucial to a robust Australian economy.

However, the size and structure of an organisation can make website design, development and maintenance a challenging task. Lack of staff time and expertise, as well as infrastructure costs, may mean that many SMEs cannot approach Web design and development strategies in the same way as large organisations (Burgess, 2011a). In Australia, just $14 \%$ of SMEs report that they are fully engaged in the opportunities of online business (Australian Communications and Media Authority, 2014).

This study was designed to examine the practice of information architecture (IA) in SMEs, within the overall endeavour of creating and maintaining an information-rich website. In a prior article that draws from this research data, Burford and Given (2013, p. 45) established that "the expertise of the professional information architect was not an ingredient in the creation of information structures for the websites of the studied SMEs". They concluded that "whilst the methodologies and profession of Web IA continue to develop and mature, they do not appear to be recognised and adopted in SMEs" (p. 47). Following these findings, this article draws attention to all of the contextual activity that surrounds the construction of an information-rich website in SMEs. The processes and practices that are revealed illuminate the complex relationship between IA and overall Web design, production and management in these particular organisational contexts.

\section{THE LITERATURE}

The importance of effective Web information structures to organisations has been recognised for almost two decades (Rosenfeld \& Morville, 1998). Evernden and Evernden (2003) stressed the need for organisations to explicitly recognise that IA requires expertise and direct investment. In a large organisational context, Morville and Rosenfeld (2006) acknowledged the importance of the business circumstances in the practice of successful IA, and recommended the alignment of business goals, culture and resources with content and users. Orna (2005) suggested that those organisations in which information is more fully treated as an asset, are those in which the practice of IA is more likely to thrive.

Texts such as Information Architecture for the World Wide Web (Morville \& Rosenfeld, 2006) have dispensed wisdom gained from extensive practical experience, and prove excellent detailed guides for practice. Morville and Rosenfeld (2006) invited the deconstruction of an IA into four systems. Organisational, labelling, navigation and search systems provide the building blocks of the IA of a website. Organising information includes adopting the most appropriate scheme or combination of schemes such as topic, task or audience, and selecting a suitable structure such as a taxonomy. Labelling systems aim to use the most understandable language to represent information on a website, and navigational systems provide global, local and embedded means to browse within the website. Search 
systems allow the user to find information based on keywords or queries, rather than browsing. Practitioners of IA are able to focus their design activities and outcomes within the specifics of each system. Wodtke and Govella (2009) adopted a similar approach to IA and simplify the detailed advice given by Morville and Rosenfeld (2006), presenting an optimal guide for the uninitiated. More broadly, empirical research surrounding the principles of design and construction that make for effective websites and intranets also informs practice. Effectiveness is defined in various ways, but its general emphasis is on usability and findability (Morville, 2005). However, much of this advice is aimed at the larger organisation, which presents a particular set of organisational conditions that impact on the effective arrangement of online information.

Research studying the conduct of IA in large organisational settings has been reported by a small number of authors. Eschenfelder (2003) researched the way in which the information structures of websites can be a battleground of organisational conflict, with different units within a large organisation looking to shape the website in ways that support their particular goals. The complexity of IA in real-life settings has been emphasised by Burford (2011, p. 2024), who studied the practice of IA in seven large organisations, and found that it was "characterised by unpredictability, multiple perspectives, and a need for responsiveness, agility, and negotiation." Meanwhile, Hider, Burford and Ferguson (2009) found wide variations in the supporting documentation that was used to guide the information design of Australian library websites.

The importance of websites with effective information structures in the smaller enterprise has been recognised by scholars such as Rathi and Given (2011) and Kim, Lee and Lee (2013). Rathi and Given (2011) examined both the usability of the websites of SMEs, and the degree to which sites are optimised for discovery in external search engines. They pointed out "many online ventures have failed not because of the products that are being sold on the website but due to the poor design of the website itself" (p. 472). Conversely, "a well designed website will invoke positive emotions, perceptions and attitudes among consumers" (p. 472). However, the website of an SME is likely to be of a lower quality than its counterpart in a large organisation (Sanders \& Galloway, 2013; Gonzalez \& Palacios, 2004).

Stockdale and Standing (2006) claimed that many SMEs have no option other than to engage in e-business in order to remain successful and in partnership with larger organisations. As large organisations design and implement e-business systems, SMEs must follow or risk losing an existing business relationship with the larger enterprise. Thompson, Williams, Thomas and Packham (2010) present an adoption ladder that depicts the progression of an SME's maturity in using the Web for business. This model suggests that threshold knowledge is needed as an SME moves to increasing levels of sophistication in their use of the Internet. A relatively simple informational website is a precursor to more significant e-business development (Thompson, Williams, Thomas \& Packham, 2010). However, the number of Australian SMEs with websites appears to have plateaued in the last few years (Australian Communications and Media Authority, 2014). In parallel, 30\% of Australian SMEs reported that they wished to improve their knowledge so that they might achieve an effective Web presence (Australian Communications and Media Authority, 2014). The digital confidence of SMEs has room for improvement. The sequential and capacitybuilding adoption model of Thompson et al. (2010) signals the importance of the informationrich website for building knowledge and skill within smaller enterprises. Furthermore, Kim et al. (2013) proposed a conceptual model of Web 2.0 use in SMEs and noted that a welldesigned website must underpin the use of social technologies: 
A well-designed and usable website is necessary not only as the company interface to the online market but also as a platform that will actively support Web 2.0 applications and crowd sourcing activities. (p.162)

Advice for Web development in SMEs is provided in the literature. Burgess, Sellitto and Karanasios (2009) discussed the development of an effective Web presence as a key strategy for the contemporary small business, and flagged some of the critical issues that should be considered, including those of hosting, building and maintaining websites, and the use of third-party support services. Burgess et al. claimed their 2009 book to be "a comprehensive attempt to draw together, in one publication, the issues faced by small business practitioners in setting up and maintaining their Web presence" (p. xiii). They sought to fill:

a major gap in that small businesses are left without guidance in relation to how to approach all aspects of setting up and maintaining their Websites. The components are out there, but there is little available in relation to how a small business might access these, or even piece them all together. (Burgess et al., 2009, p. 1)

Burgess et al. (2009) critiqued previous models of small business website development, and explored the limitations of the guidance provided by agencies that are tasked to support the smaller enterprise in pursuit of an optimal online presence. However, the detailed advice of Burgess et al. (2009) to the small business manager is devoid of guidance on the importance and the processes of Web IA. Instead, they proposed a set of "essential features to be incorporated when designing a Website" (p. 39) and recommended good practice processes in usability, accessibility, markup, and metadata.

Burgess (2011a) introduced a relatively simple "audit tool" for small businesses to track and manage their Web presence, which may extend beyond the SME's website to portals and directories and other third party platforms. The tool covers several dimensions of Web presence, including the Web as provider of information about the business, and also the extent of its support for communication, distribution and transaction. Burgess (2011a) found that information features were seen to be the most important on small businesses own website and on third party websites.

While much of the literature spells out what SMEs should do in order to flourish in an era of online information, it does not dwell extensively on how they should attend to information for the Web. Focused advice on the structuring of online information is absent in this context. Clearly, the how is dependent on organisational considerations, yet SMEs are given less coverage in the professional guides, and research in this domain has been focused on larger-scale settings. As a consequence, Burford and Given (2013) reported that the information structures of the websites of the five studied SMEs are less than optimal and are difficult to maintain in a coherent manner. They reported significant navigational, organisational and labelling inadequacies in these information-rich websites.

A review of the literature established that a research gap exists. IA research and practice leaders have focused their attentions on larger organisations leaving IA in the context of smaller organisations devoid of theoretical attention. The rhetoric of the importance of a Web presence to SMEs permeates the literature, and frameworks of advice for website development within SMEs are provided. Yet this guidance omits the all-important work of IA. This paper begins the task of developing an understanding of the context for IA in SMEs, and complements those descriptions of larger-scale Web IA. 


\section{RESEARCH DESIGN}

This investigation sought to better understand the various activities in SMEs in the development of an information-rich website with a focus on architecting online information structures. The study adopted the Australian Bureau of Statistics' (2002) definition of SMEs as having 1-199 employees. The particular contextual issues, obstacles and successes that are experienced by those that practice IA in SMEs were explored.

Framed by a case study methodology, this research used SMEs as units of analysis. Yin (2009) defined the case study as an empirical inquiry that investigates a contemporary phenomenon within its real-life context. Hartley (2004, p. 323) claimed that "case studies can be useful for exploring new or emerging processes or behaviours" and understanding "how behaviour and/or processes are influenced by, and influence context." A case study approach to knowing more about how SMEs are designing online information structures is applicable because contextual insights and patterns can only be revealed by examining situated practice. This research was designed as a "particularistic" (Merriam, 1998, p. 29), multiple, case study - i.e. it examined a particular phenomenon across five SME contexts. Each case was important for what it revealed about the conduct of Web IA in organisations. It was purposely designed to generalise and find patterns rather than describe how IA is practiced in any particular organisation.

This study focuses on information-rich websites that have need of IA. Orna (2005, p. 14) distinguished between organisations that create information products such as websites that "embody substantial information content which aims to allow users to do something they need/want to do" and those that evoke feelings in order to market or advertise. This research focused on the use of the Web for "telling" or informing to support business goals, rather than to persuade, advertise or sell.

SMEs with websites that are publicly accessible and predominantly used to inform clients were invited to participate in the research. The researchers examined the websites of a number of SMEs, to confirm that they were information-rich and that the organisation could be classified as a SME. A person in a leadership position within each SME was contacted with a request that the SME participate in the research. With that agreement in place, a dialogue between the researchers and the person in authority pinpointed the individual(s) who had most input to the creation of the information-rich website. Six organisations were approached and five agreed to participate.

Organisations were drawn from various sectors; they were selected to establish a diverse range in purpose and business model. All other conditions and circumstances within the organisations studied were considered context for this situated study. Table 1 depicts the broad business approach and the size in staff numbers of all the studied organisations. Organisation $\mathrm{C}$ is noticeably larger than all others; however all organisations conform to the definition of SME and are treated as a homogenous set of data in this study.

An interpretive research paradigm drove the collection and analysis of qualitative data from the five SMEs. The story of the practice of Web IA within a website redevelopment was captured from the person or group of people with responsibility and involvement in structuring online information. The data, derived from the focus group held in each organisation, was captured in digital audio format, and transcribed using a professional transcription company. In an inductive approach to analysis, the data were coded using the NVivo software as a supporting analytic tool to reveal patterns and themes across SMEs. Thematic analysis captures some level of patterned meaning within the data (Braun \& Clarke, 
Table 1. Summary data of the studied SMEs

\begin{tabular}{llclll}
\hline Org & Business Model & $\begin{array}{c}\text { Approximate } \\
\text { staff numbers }\end{array}$ & \multicolumn{3}{c}{ Responsible person for website } \\
\cline { 3 - 6 } & & & $\begin{array}{l}\text { Length of } \\
\text { service }\end{array}$ & $\begin{array}{l}\text { Role in the } \\
\text { organisation }\end{array}$ & $\begin{array}{l}\text { Disciplinary } \\
\text { qualifications }\end{array}$ \\
\hline A & Private & 90 & 9 months & $\begin{array}{l}\text { Head of } \\
\text { Education }\end{array}$ & Graphic design \\
B & $\begin{array}{l}\text { Semi-autonomous } \\
\text { and semi self-funded }\end{array}$ & 15 & 6 months & $\begin{array}{l}\text { Marketing } \\
\text { Manager }\end{array}$ & Marketing \\
C & Members Society & 110 & 1 year & $\begin{array}{l}\text { Web Master } \\
\text { Marketing }\end{array}$ & $\begin{array}{l}\text { Journalism } \\
\text { Marketing } \\
\text { D } \quad \text { Government funded }\end{array}$ \\
& 15 & 6 months & $\begin{array}{l}\text { Manager } \\
\text { Director of }\end{array}$ & $\begin{array}{l}\text { Business } \\
\text { Administration }\end{array}$ \\
E & Private & 15 & 6 years & $\begin{array}{l}\text { Business } \\
\text { Development }\end{array}$ & \\
\hline
\end{tabular}

2006), and provides theoretical freedom to approach a complex body of data and reveal themes and insights without pre-existing expectations or existing coding frames.

\section{FINDINGS AND DISCUSSION}

An information-rich website for an SME is a tightly integrated outcome of multiple skills, practices and products. Whilst a cohesive approach and seamless outcomes are optimal, this research finds that best practice leading to usable websites and findable information remains elusive. The paper reports in four themes: (1) Owning the project, (2) Models of practice, (3) Interacting at the boundaries, and (4) Maintaining the information and its structure.

\section{Owning the website}

In keeping with the literature (e.g., Carree et al., 2002; Howcroft, 2001), the studied SMEs considered the enterprise website as an important medium for informing, marketing and communicating. They demonstrated a desire to create an effective Web presence to meet business goals. A high-quality website was ever sought and the role of SME management was "to set a high level of expectations around the website design and implementation" (Org A). Redevelopment projects were never far apart: "as soon as we received word that we were getting funded for another two years we decided one of the most important things to do was improve the website" (Org B). There was an organisational obligation to have a clear vision for the website development and to appropriately engage the services of a heterogeneous industry to locate the right support and service to implement the SME's goals. In the context of large organisations, Burford (2014) introduces the notion of owning the website as a precursor to owning $\mathrm{WebIA}$. Organisations that back the rhetoric of website as vital to organisational success, with responsibility, attention and resourcing are considered to be owning the website. Although the seven large organisations that Burford (2014) studied were inconsistent in owning the website, the five SMEs in this study were unanimously attentive to the enterprise website. 
Throughout a Web development project, the SMEs maintained a sense of responsibility. It was a Web developer's task to "help us select a platform that's going to give us ability to do the maintenance" (Org A). The Web developer played only a supporting role in the selection of platform. In another organisation, a fierce sense of ownership and authority for the website development was reported:

And I think this is the biggest struggle at the moment, that if you have the structural engineers and architects govern the look and the modus operandi of it, I think that's when you get stuffed.... we've got to look at it from a business perspective.... so we tell the engineer what we want. (Org C)

A key concern of the SMEs was that the website reveal the organisation's identity and a branding message that was consistent with all other forms of communication. Clear direction was given that the website would be part of a larger and consistent message to clients.

So we'd spent a lot of time and effort coming up with a new corporate identity and the first embodiment of that was our hard copy brochure. I wanted to make sure that we were capturing the value that we'd created from that in our website. (Org A)

Responsibility for website development was anchored with an existing employee within the SME who was responsible for the project and its management. This person combined the task of website development with other duties and roles within the organisation, confirming Thompson et al.'s (2010, p. 2) claim that SMEs are reliant on "their staff taking a more generalist approach covering a wider variety of responsibilities" when embracing the Internet for business.

The decision to outsource the various facets of website development was common in all the studied SMEs. When asked if they had made the right decision in outsourcing, if they had the right mix of in-house and external contribution, SMEs were confident in the approach taken. "I wouldn't say too dependent, I'd say we're dependent when we need to be" (Org D). They claimed an awareness of their own capability and when to acknowledge a gap that needed to be filled:

At the time we knew that we didn't have the level of sophistication to do it ourselves so we knew that we needed to get somebody else to do it. (Org D)

The rationale for outsourcing was access to expertise. Specialist expertise in a person employed within the SME could not be fully utilised. Sanders and Galloway (2013) note that the websites of the smaller enterprise suffer in quality from the input of the non-specialist; meanwhile the option to "hire an in-house developer and an in-house designer as well" (Org B) that were not needed long term did not make good business sense. Access to expertise and economies of scale drove the outsourcing.

When choosing an agency in which to entrust the design and development of the website, SMEs adopted a tendering process and indicated that a known company of good reputation was of prime importance. Price, reputation and an ability to deliver were three key selection criteria. "We went to market to find basically the best agency who could give us the best website for our limited expense" (Org B). Another SME confirmed this approach: 
We put together the brief and we went out and tendered to three companies to provide the service. All three were people who had done work or people we either knew or had seen their products before. We weren't going into any of these people blind which was helpful. (Org A)

SMEs were wary about the market place of Web development. They perceived a great variation in service and outcome. Concerns were expressed about clearly matching the requirements of the SME to the capability and intentions of the Web development company. One SME reported that the agency that they had engaged had not quoted accurately and whilst a quality product had been delivered, one research participant "certainly got the feeling that they really weren't confident, looking at the brief and coming up with a figure that was actually right" (Org A). Others complicated the design to justify the cost:

... we saw some of the quotes back based on the same brief were vastly more complicated than what we actually wanted. I think sometimes that was there to justify the higher price. (Org A)

Awareness and caution were exercised around global competition in the Web development industry "because of this distortion in the market of overseas developers" (Org A). All SMEs, some after bitter experience, were looking for Australian companies that were perceived to be more likely to deliver a quality service.

The reality is that we were not comparing this with cheap offshore built websites. We wanted a quality product and we wanted to make sure that we had someone close by that we could go and bang on the door if it wasn't quite right. (Org A)

SMEs were found to take and retain a sense of ownership and responsibility for website creation and maintenance. They readily engaged in the marketplace of the Web development industry to provide online information that they knew was critical to business success. In the next section, the way in which they engaged is discussed. The way in which expertise, technology, designs and practice were sourced or performed is reported.

\section{Models of practice}

SMEs exhibited various flawed pathways in creating an enterprise website. However, at the core of the website development, all of the studied SMEs elected to have the technical build of the website outsourced to a Web development agency. This is consistent with claims in the literature that SMEs do not have ready internal technical capacity (e.g., Burgess, 2011b; Bingley, Urwin, Hunter \& Burgess, 2010).

The preferred business model of the Web development agencies was to request detailed, explicit Web design specifications in order to build the website. In this, all design activities were separated from the Web developers' sphere of responsibility:

The agency that we went to, they're very much a "tell us what you need and we'll build it for you but you have to tell us what you want, where you want it and why you want it." And so I had to go to them with a brief that was pretty comprehensive. (Org D) 
Thus, all aspects of the preparation and design of the site, the graphic design, the Web IA, the writing of content, and, in some cases, populating the site with content, were orchestrated by the SME. In these component activities of website development, the SME took responsibility for some activities and outsourced others to third party agencies. The greatest challenge was to efficiently and effectively identify, isolate and recombine the component aspects of website design and development. Burgess et al. (2009, p. 18) noted the lack of guidance to SMEs in "how to approach all aspects of establishing and maintaining their Web presence" and this study confirms a continued gap. The relationship and communication channels between the external agencies were variously arranged. One SME had contracted three agencies: one to build the site, another to focus on graphic design and visual identity, and a third to determine writing style and write content. They all had specific yet overlapping duties. Duplication arose:

Basically there are two sections of research and analysis happening at the same time, $\mathrm{XXXXX}$ is running analysis and YYYYY are also running analysis. So both are working to apply that knowledge to the website development. (Org B)

When asked which of these external agencies were responsible for IA, the research participant replied "both" and continued to explain the realisation that only one agency could deliver the final information design. In this instance, it was noted that the agencies were working well together:

Normally it's just one agency or one Web developer, send the work to them, get them to do it. Although, they're actually working as a great team. YYYYY will deliver the final IA. They're overseeing, because we had to choose. (Org B)

Still this SME did not have all aspects of Web development covered. There was no one to attend to the consistent style and writing of content. "Well the thing that we're missing at the moment is the voice for our copywriting" (Org B). Yet another external agency is engaged:

We've also got a PR agency who's working on some other stuff for us. They'll be writing a lot of the journalistic stuff for us, they'll be writing in line with the voice that's being established between them and our ad agency YYYYY. (Org B)

In another organisation the model was different. It was Web development and search engine optimisation (SEO) that had been isolated for outsourcing. "We split our Web stuff into the creation of the actual website and we've got, we've engaged another organisation to do our site optimisation" (Org D). The decision to approach Web development in this way was made before this research participant was employed and he was unable to provide a rationale.

In another SME, a communication agency had been contracted to manage the entire initiative as a project. That external agency, unable itself to provide the skills that were needed to fulfil the commission, outsourced them to another agency. When the in-house skillsets of external agencies are lacking they are likely to sub-contract to even more remote parties.

The IA went overseas, was done overseas. And the backend construction as well. They had contracted the actual production and the IA and requirements to overseas. (Org B) 
Thus with varying competency, the studied SMEs engaged in aspects of planning and design of the website. They listed the skills and roles that must be marshalled. "So we're looking at who do we need to be involved, so the list was... there's the designer, the developer, the copywriter, the editing - and I'm really fussy about the editing" (Org C). But the ability of an SME to select and integrate the skills and outputs of the various agents involved in the development of the website was troubled - in one case, to the extent that the website did not eventuate.

The decision was made to sort of split it up among a number of different companiesto do different components - so one of the big components was the design, the pretty pictures type - but the big part basically failed because so many different people were involved - the whole thing just fell in a heap. (Org E)

SMEs outsource the activities involved in the creation of an information-rich website in various and individualistic configurations. A lack of documented practice or theoretical knowledge about how to approach the build of a website for the smaller enterprise, particularly the Web IA, pushes SMEs to a reactive, best-effort that does not always produce effective practices and outcomes. At the boundaries of their interactions with external agencies, SMEs encounter uncertainties and mis-communications.

\section{Interacting at the boundaries}

The various boundaries between agencies and the SME or other agencies were a negotiated space with opportunity and frustration. One SME reported that, in the detailed specification to a Web development agency, she omitted to include the need for a search engine.

Nevertheless, a search tool was included in the technical build of the site along with other unrequested features that appeared to be standard in all websites that the agency developed:

It's the same as, I didn't put in that little thingy that you get on pages that you can copy it to Facebook ... those little icons. I didn't ask for that but I got it anyway. I think that was just standard you know. (Org D)

However, there were times when expectations and communications between an SME and the various agencies involved in the website design and development were not fruitful.

Frustration was expressed by a research participant who could not communicate the essence of her organisation to a graphic design company.

We went to XXXX Design, who were the whiz bang guru graphic designers around, and we went into the funky studio and met with all the boys in their sneakers, they came back with the most boring image I've ever seen in my life, and I said to them, "This is suitable for an insurance company, but not for us". So they went back to the drawing board, and they came back with two more boring ones, and I just said, "I'm sorry, this is not working, I don't seem to be able to communicate with you." (Org C)

This situation was resolved when the SME took back control of the creative input and specified what was needed: "We ended up telling them the way we wanted it designed, and how we wanted it to be done" (Org C). 
Doubt and frustration occurred in another SME when the commissioned Web development agency became unresponsive to any communication from the SME during the development time frame that had been promised. The SME's greatest concern was that the Web developers had underquoted, and for that reason the commission was never a priority. Concern escalated to the point that the SME contacted the agency to ask if they had underquoted and if they needed to re-quote.

For a week they didn't return phone calls and so suddenly another week, and then they'd turn around stuff occasionally in a day, and others two weeks. It was just, communication was appalling with the company and that was the part that was most frustrating. And just that lack of communication led to a lack of confidence. (Org B)

One research participant described the process of going live with a new site and replacing the old one as a source of impossible communication. The technical description of the process was beyond the understanding of the SME website manager. Matching up pages, redirecting pages and pointing people back to the homepage was a conversation in which the SME could not engage. As a solution another agency that the SME had employed for search engine optimisation, was used to interpret the technical information that was required for the implementation:

That was where it got tricky. The language started getting a little bit, OK guys, I do not know what you're talking about! I would have to say it wasn't an easy process because we got to a point where I got to the end of my understanding. I ended up saying to our site optimisation people "I need you to talk to these guys because I don't understand what it is they're talking about". (Org D)

With best-possible decisions made to outsource components of an information-rich website construction, there is constant negotiation, communication and refinement at the boundaries between SMEs and the outsourced expertise. Technical language is at times deficient in SMEs, external agencies are tardy, and expectations are unmet. Yet, a website is created and SMEs have particular intentions about how the maintenance of information will be achieved.

\section{Maintaining the information and its structure}

SMEs adopted open-source content management systems for the easy maintenance of the website. Either WordPress or Drupal were used in all of the studied SMEs. This decision was a negotiation with the Web development agency and based largely on the technical expertise and preference of the agency. In one SME, a decision to use Drupal coincided with the fact that "the developer that we're using is quite proactive in the Drupal community" (Org D).

Thompson et al. (2010) identified that, once developed, a simple informational website is frequently unable to be maintained by an SME. Burgess et al. (2009) warned of "the time delays and heavy costs associated with content being updated by an external party" (p.38). This study suggests that SMEs have learned the need to be able to independently edit, add and delete the content of the website. Previous websites had been developed by external agencies that had retained the authority to edit content. The maintenance of information on the website was fraught. "The current system was something that couldn't be changed in-house; it had to be changed via the agency, which had to change it via their contractor" (Org B). Generally, the experience had been "that website was externally hosted; it was a nightmare to maintain" 
(Org E). Thus, all SMEs had or were intent on establishing circumstances that allowed independence in editing the information on the organisation's website.

So we decided to move away from that - we wanted something that was manageable internally. We didn't want to have a situation where any change had to be done by a third party. (Org A)

The maintenance of content was achieved by templates or proforma, which provide structured options for the in-house editor.

All I need to do is log on, bring up the edit function. It asks me what I want to do, do I want to create featured research, do I want to create a news item, do I want to add a staff member? And lets me do whatever I want within the parameters of what the site can actually do. (Org D)

Although this situation represented an advance in SME independence in maintaining information currency on the website, some limitations remained. Updating and adding or deleting similar content could be done in-house, yet information maintenance was restricted to the existing structures of the IA.

They actually can create copy within certain areas. They can create new postings, that's fine. They can edit things within certain areas but they can't, no-one can muck around with the structure. (Org E)

Problems in maintaining the IA continued. The IA of the website of SMEs could not be altered. All Web development companies remained available to the SMEs should technical support be needed. They provided "backup at an hourly rate" (Org D). When asked what would be done if another tier or category of information was needed on the site, all agreed that they would go back to the Web developer. Yet incremental changes to the IA initiated by the SME and implemented by a Web developer were reported to produce fraught outcomes.

Over time, over the next few years there were so many additions and changes made that it really lost its structure. And lost its ease of use as more pages were just dropped in here, little features were dropped in there. What happened is there was no strategy behind it anymore. (Org B)

IA is a component of website design that is frequently undertaken by employees within a SME or a small outsourced agency, and is created without the application of expertise. Once the website is launched, some in-house guardianship of the IA is likely: "what I'd be really careful to avoid is having multiple links to exactly the same page, from a home page because it's ridiculous" (Org E). Yet strategies for a scalable and maintainable IA were not in place. "So it just organically grew into an absolute hodge-podge" (Org E). The outcome of the situated practice of IA in SMEs does not stand the test of time.

\section{IMPLICATIONS FOR RESEARCH AND PRACTICE}

From a research perspective, this study highlights the need for greater empirical knowledge of the theory and practice of Web IA and its restrictions in the SME environment. It suggests 
that Web IA and its allied practices in the smaller enterprise are severely under-researched and under-theorised in the practice environment. Whilst SMEs exert significant effort in the development of an information-rich website, they are poorly informed or influenced by expertise and theory. Web IA in large organisations knows many practice-based experts, such as Morville and Rosenfeld (2006), Hobbs, Fenn and Resmini (2010), and Wodtke and Govella (2009). Yet the circumstances of SMEs have not won the attention of practice and thought leaders in IA. Until now SMEs have not profited from the attention that researchers apply to the situated practice of Web IA in larger enterprises, nor the recommendations of best practice from industry leaders. This yields a context in which very little empirical knowledge or best-practice guidance is available for the work of Web IA in SMEs. The IA of the websites of the five studied SMEs is found wanting in the component aspects of an IA: navigation, labelling and organisation (Burford \& Given 2013). Theory and knowledge about Web IA must be crafted and communicated in a suitable form for the SME practitioner. This article commences the attention that is required.

A number of key findings point to specific areas of improvement that are required in the process of information-rich website implementation in SMEs. Overall, the ability to manage all phases of Web design and development in-house (including future updates of content) is vital to the success of an organisation's online strategy. Staff with the knowledge and attitude needed to embed appropriate IA in the development of the enterprise website is crucial in ensuring that the organisation's online strategy is achieved. Although outsourcing particular activities may make financial sense in the short term, an SME must have embedded capability in managing both the commissions and the process of merging various commissioned outcomes into an effective website.

Where outsourcing of particular activities is unavoidable, it is important that SMEs manage and maintain appropriate communications strategies. Outsourcing to a Web design or development firm with an established track record in a related industry proves important. Further, design firms with a long history of successful projects will be more likely to be available to provide support and re-development work in the longer term. Understanding the organisation's mission is vital to Web branding and the choice of Web technologies and tools most appropriate to an SME's staff and clientele. SMEs must ask the right questions of potential outsourcers to ensure that the long-term design goals of the organisation will be met. Questions, for example, related to user testing, future revisions/redesigns, integration of new media and staff turnover need to be explored in the contracting process.

The component complexities of Web design and development, alongside the implementation of appropriate IA, were explored in five SMEs in this project. However, a larger sample of organisations is needed to present a more complete picture of practice and its challenges. Characteristics unique to not-for-profit SMEs could be compared to profit-seeking organisations, where the available expertise, infrastructure, resources and other elements may result in quite different design decisions. Furthermore, until an organisational ability to create and maintain an effective website is achieved, it is unlikely that it can be progressed to a site of e-Business (Thompson et al., 2010) or a suitable springboard for social media (Kim et al., 2013). As more and more SMEs embrace social media and other new (especially, free) tools for use alongside website information provision, it would be useful to explore the integration of these various media and the implications for Web IA.

Finally, there are practice implications for the education and training of staff within Web development firms. Given the importance of Web IA in the development and management of websites that have a primary purpose to inform, it is vital that Web designers and developers are skilled in Web IA. Burford and Given (2013) demonstrated that many 
SMEs place responsibility for Web IA in the hands of those who lack the disciplinary background and skill needed to achieve an effective outcome. Ensuring that in-house or contracted staff have the required skills to develop and implement a Web IA that meets the SME's goals is vital to a successful online presence.

\section{CONCLUSION}

The development of an information-rich website by an SME is a busy, fragmented set of practices, communications and assemblages. In the absence of theoretical or practice advice, SMEs take up the challenge to create a website to support the business endeavour with a strong sense of responsibility. Where in-house confidence or expertise is lacking, SMEs outsource component aspects of the website development and make best-effort attempts to assemble the multiple practice outcomes into an enterprise website. IA is a design activity that is often undertaken within the SME, and is rarely guided by expertise and the expanding knowledge base of IA at large.

\section{REFERENCES}

Australian Bureau of Statistics (ABS). (2002). Small business in Australia. Retrieved from http://www.abs.gov.au/ausstats/abs@.nsf/mf/1321.0

Australian Communications and Media Authority (ACMA). (2014). Australian SMEs in the digital economy (Report 1, Communication report series 2012-2013). Retrieved from http://www.acma.gov.au/theACMA/engage-blogs/engage-blogs/researchacma/SMEskey-drivers-of-the-digital-economy.

Bingley, S., Urwin, G., Hunter, M. G., \& Burgess, A. (2010). Website development and use in CBOs: A knowledge management perspective. International Journal of Interdisciplinary Social Sciences, 5(5), 327-338.

Braun, V., \& Clarke, V. (2006). Using thematic analysis in psychology. Qualitative Research in Psychology, 3(2), 77-101.

Burford, S. (2011). Complexity and the practice of Web information architecture. Journal of the American Society for Information Science and Technology, 62(10), 2024-2037.

Burford, S. (2014). A grounded theory of the practice of Web information architecture in large organizations. Journal of the American Society for Information Science and Technology, (early view). doi:10.1002/asi.23098.

Burford, S., \& Given, L. M. (2013). The practitioners of Web information architecture in small and medium enterprises. Journal of Information Architecture, 5(1-2), 31-49.

Burgess, S. (2011a). The use of third party website providers by Australian small businesses. International Journal of the Digital Society, 2(1), 328-336.

Burgess, S. (2011b). Specifications for a Website audit tool for small businesses. In M.M. Cruz-Cunha \& J. Varajão (Eds.), E-Business issues, challenges and opportunities for SMEs: Driving competitiveness (pp. 229-245). Hershey, PA: Business Science Reference.

Burgess, S., Sellitto, C., \& Karanasios, S. (2009). Effective Web presence solutions for small businesses: Strategies for successful implementation. Hershey, PA: IGI Global.

Carree, M., van Stel, A., Thurik, R., \& Wennekers, S. (2002). Economic development and business ownership: an analysis using data of 23 OECD countries in the period 19761996. Small Business Economics, 19(3) 271-290. 
Eschenfelder, K. (2003). The customer is always right, but whose customer is more important? Conflict and Web site classification schemes. Information Technology and People, 16(4), 419-439.

Evernden, R., \& Evernden, E. (2003). Information first: Integrating knowledge and information architecture for business advantage. Oxford: Butterworth-Heinemann.

Gonzalez, F., \& Palacios, T. (2004). Quantitative evaluation of commercial websites: an empirical study of Spanish firms. International Journal of Information Management, 24(4), 313-328.

Hartley, J. (2004). Case study research. In C. Cassell \& G. Symon (Eds.) Essential guide to qualitative methods in organisational research (pp. 323-333). London: Sage.

Hider, P., Burford, S., \& Ferguson, S. (2009). The use of supporting documentation for information architecture by Australian libraries. Journal of Web Librarianship, 3(1), $55-70$.

Hobbs, J., Fenn, T., \& Resmini, A. (2010). Maturing a practice. Journal of Information Architecture. 2(1), 37-54.

Howcroft, D. (2001). After the goldrush: deconstructing the myths of the dot.com market. Journal of Information Technology, 16(4), 195-204.

Kim, H. D., Lee, I. \& Lee, C. K. (2013). Building Web 2.0 enterprises: A study of small and medium enterprises in the United States. International Small Business Journal, 31(2), 156-174.

Merriam, S. (1998). Qualitative research and case study applications in education. San Francisco, CA: Jossey-Bass Publishers.

Morville, P. (2005). Ambient findability. Sebastopol, CA: O'Reilly.

Morville, P., \& Rosenfeld, L. (2006). Information architecture for the World Wide Web (3rd ed.). Sebastopol, CA: O'Reilly.

Orna, E. (2005). Making knowledge visible. Aldershot, Hants: Gower Publishing.

Rathi, D., \& Given, L. M. (2011). Designing digital marketplaces for competitive advantage. In M. Cruz-Cunha, \& J. Varajão (Eds.), E-Business issues, challenges and opportunities for SMEs: Driving competitiveness (pp. 1-19). Hershey, PA: Business Science Reference, IGI Global Publishing.

Rosenfeld, L. \& Morville, P. (1998). Information architecture for the World Wide Web. Sebastopol, CA: O'Reilly and Associates.

Sanders J. \& Galloway, L. (2013). Rural small firms' website quality in transition and market economies. Journal of Small Business and Enterprise Development, 20(4), 788-806.

Stockdale, R. \& Standing, C. (2006). A classification model to support SME e-commerce adoption initiatives. Journal of Small Business and Enterprise Development, 13(3) 381394.

Thompson, P., Williams, R., Thomas, B. \& Packham, G. (2010). Shortages of IT skills in UK SMEs. In Proceedings of Institute for Small Business and Entrepreneurship Conference, November, London, 2010. Retrieved from http://www.isbe.org.uk/ThompsonPi10

Wodtke, C. \& Govella, A. (2009). Information Architecture: Blueprints for the web (2nd ed.). Berkeley, CA: New Riders.

Yin, R. K. (2009). Case study research: Design and methods (4th ed.). Thousand Oaks, CA: Sage. 